\title{
The Early Growth and Development Study: A Prospective Adoption Study from Birth Through Middle Childhood
}

\author{
Leslie D. Leve ${ }^{1}$, Jenae M. Neiderhiser², Daniel S. Shaw ${ }^{3}$, Jody Ganiban ${ }^{4}$, Misaki N. \\ Natsuaki ${ }^{5}$, and David Reiss ${ }^{6}$ \\ ${ }^{1}$ Oregon Social Learning Center, Eugene, Oregon, United States of America \\ ${ }^{2}$ The Pennsylvania State University, Department of Psychology, University Park, Pennsylvania, \\ United States of America \\ ${ }^{3}$ University of Pittsburgh, Department of Psychology, Pittsburgh, Pennsylvania, United States of \\ America \\ ${ }^{4}$ Center for Family Research, George Washington University, Washington DC, United States of \\ America \\ ${ }^{5}$ The University of California, Riverside, Department of Psychology, Riverside, California, United \\ States of America \\ ${ }^{6}$ Yale Child Study Center, Yale School of Medicine, New Haven, Connecticut, United States of \\ America
}

\section{Abstract}

The Early Growth and Development Study is a prospective adoption study of birth parents, adoptive parents, and adopted children recruited in two cohorts ( $N=561$ triads). The primary study aims are to examine how family, peer, and contextual processes affect children's adjustment, and to examine their interplay (mediation, moderation) with genetic influences. Participants were recruited through adoption agencies located throughout the United States following the birth of a child. Assessments are ongoing, in 9-month intervals until the child reaches 3 years of age and in one-year intervals thereafter through age 9. Data collection includes the following primary constructs: child temperament, social behavior, school performance, mental health, and health; birth and adoptive parent personality characteristics, mental health, competence, stress, health, context, substance use, parenting, and marital relations; and pregnancy use of drugs and maternal stress during pregnancy. DNA and salivary cortisol samples have also been collected. Analyses have indicated evidence for genotype-environment interactions during early childhood. Study procedures, sample representativeness (including tests of potential confounds in the adoption design), and an overview of findings to date are summarized, and future plans are described.

\section{Keywords}

adoption; childhood; longitudinal; genetic; parenting; birth parent

Longitudinal and cross-sectional studies have shown that heritable child characteristics influence parents' behavior towards their children (Dunn et al., 1986; Neiderhiser et al., 2007; Reiss et al., 2000). For example, heritable hostile behavior in adolescent adoptees has

Address for correspondence: Leslie D. Leve, Oregon Social Learning Center, 10 Shelton McMurphey Blvd., Eugene, OR 97401-4928, USA. lesliel@oslc.org. 
been shown to evoke harsh disciplinary practices in adoptive parents (evocative genotypeenvironment correlation ( $I \mathrm{GE}$ ); Ge et al., 1996). The effects of heritable child characteristics on parents have also been found in the preschool and school entry periods (Deater-Deckard, 2000; Deater-Deckard \& O'Connor, 2000). In addition, family context and parenting processes may be moderated by genetic influences. Twin, adoption, and molecular genetic studies have found significant Genotype $\times$ Environment $(\mathrm{G} \times \mathrm{E})$ interaction effects for the development of conduct disorder and aggression in adolescence, antisocial personality disorder in adults, and depression in women (Button et al., 2005; Cadoret et al., 1995, 1996). Using adoption designs, such $\mathrm{G} \times \mathrm{E}$ interactions have also been identified in early childhood (e.g., Leve et al., 2009; Natsuaki et al., 2010), when child behavior has proven to be amenable to intervention (Olds et al., 2005). However, adoption studies prospectively examining social processes during early childhood are rare, with the current study and the Colorado Adoption Project (Plomin \& DeFries, 1985) being the only such studies to date.

Most findings of evocative $r \mathrm{GE}$ effects are from twin studies. Because twin offspring inherit $50 \%$ of their genes from each parent, it is difficult to disentangle the effects of the child's genes from those of their parents' when examining associations between parent and child phenotypes (e.g., evocative $r \mathrm{GE}$ associations may be confounded by passive $r \mathrm{GE}$ effects). The adoption design is a powerful method for estimating evocative $r \mathrm{GE}$ effects because adoption is a natural experiment in which children are reared in families where they are genetically unrelated to their caretakers (Haugaard \& Hazan, 2003; Plomin, DeFries, Knopik, \& Neiderhiser, 2013). In the adoption design, similarities between birth parents and the adopted child suggest genetic influences (due to shared genes and a lack of shared rearing environments). Similarities between adoptive parents and adopted children indicate environmental processes (due to shared rearing environments and the lack of shared genes), although evocative $r \mathrm{GE}$ effects may also cause parent-child similarities.

\section{Overview of Current Study}

This report provides an update on the goals, results, and plans of the Early Growth and Development Study (EGDS; see Leve et al., 2007, for our initial report on this study). The EGDS is a prospective adoption study designed to examine specific features of families, peers, and social contexts that affect child adjustment, that may mediate the expression of genetic influences, and/or that may be moderated by (or moderate) genetic influences. The EGDS is comprised of multiple, inter-related studies, each spanning a different developmental period and with unique foci (further described in the Primary Study Hypotheses and Aims section, below). To date, we have focused on cross-sectional as well as longitudinal associations, from infancy through to age 9 . The investigation of $\mathrm{G} \times \mathrm{E}$ interaction effects and genotype-environment correlation ( $I \mathrm{GE})$ can provide crucial information about malleable environmental processes that might reduce adverse genetic risk and enhance child outcomes. Thus, a second goal of the EGDS is to systematically identify specific family and peer processes and maladaptive conditions that could serve as malleable targets for intervention. The study includes 561 adoption triads consisting of the child, the child's adoptive parents, and the child's birth parent(s). By focusing on family processes beginning in infancy, the EGDS provides a unique opportunity to detect GE interplay when first expressed and examine its unfolding over time.

\section{Guiding Theoretical Model}

Our theoretical model was derived from research indicating family process predictors of, and continuities within, five life course developmental pathways: internalizing behavior, externalizing behavior, social competence, school adjustment, and healthy weight. The patterns of life course development in each of these pathways are well supported by existing 
genetic and phenotypic data (e.g., Birch \& Davison, 2001; Caspi et al., 1995; Eisenberg et al., 2003; Gilliom \& Shaw, 2004). To select phenotypes (and subsequent measures) to test our hypotheses, we relied on three types of studies: adoption studies to identify phenotypes that are known to be linked between birth parent and adopted child, and to also be influenced by the environment (e.g., Ge et al., 1996); twin and sibling studies to identify phenotypes that have known genetic and environmental influences (e.g., Petrill et al., 2006); and life course studies to identify how a phenotype might change or evolve across development (e.g., Caspi \& Roberts, 2001). Individually, these approaches have limitations as guiding methodologies. For example, the knowledge base from adoption studies is quite small, twin and sibling studies generally do not permit a comparison of phenotypes between generations, and life course studies without a genetically sensitive component cannot distinguish between phenotypic stability due to environmental versus genetic influences. Considered together, however, these three lines of work have facilitated our development of data-based hypotheses about probable birth parent-adopted child phenotypic similarities and likely environmental influences on these genetically-influenced phenotypes. For instance, converging evidence from twin, adoption, and life course studies indicates five sets of phenotypes that are genetically-linked across generations, and for which there are known environmental influences: (1) birth parent anxiety and child fearful temperament, (2) birth parent antisocial behavior and child impulsivity, (3) birth parent sociability and child positive affect, (4) birth parent cognitive function and child cognitive skills, and (5) birth parent body mass index (BMI) and child BMI.

\section{Primary Study Hypotheses and Aims}

The conceptual model for the EGDS is based on the following general hypotheses: (1) parenting behaviors, marital dynamics, and peer behaviors will have main effects on child adjustment (replicating prior studies that have found such associations among geneticallyrelated family members); (2) genetic influences of the child will evoke specific reactions and interactions from their social environment (parenting, marital relations, peer behaviors) (evocative $r \mathrm{GE}$ ); (3) environmental main effects will be moderated by and moderate genetic influences $(\mathrm{G} \times \mathrm{E})$, at times offsetting genetically-influenced risks and at times enhancing genetically-influenced strengths; (4) child and parenting behaviors will show both change and continuity across development, with child behavioral continuity associated with both environmental and genetic influences; and (5) the environmental context may enhance the effects that genetically-influenced child behaviors have on parenting practices (e.g., genetically-influenced effects of child characteristics on parenting may only appear in certain contexts; moderation of evocative $r \mathrm{GE}$ ). Within this model, we hypothesize specific mediating and moderating mechanisms on adjustment along five developmental pathways: externalizing behavior, internalizing behavior, social competence, school performance, and weight trajectories.

The EGDS comprises several related and interdependent grants that share the following primary aims. Aim 1 is to conduct longitudinal model testing free from the influences of shared genes to identify early emerging behaviors and emotions in children that predict later behavioral, psychiatric, and health outcomes across early to middle childhood. Aim 2 is to isolate genetic and environmental influences using a behavioral approach. Here we aim to estimate postnatal family environmental effects independent of genetic variability and prenatal exposures, and genetic influences independent of postnatal and prenatal influences. Aim 3 is to address the question of how genetic influences affect the social environment by examining the mediating role of the rearing environment on genetic influences on child outcomes (evocative $r \mathrm{GE}$ ). Aim 4 is to examine how the interaction between genetic and environmental processes influences child outcomes by examining the moderating role of the 
rearing environment on prenatal and genetic influences on child outcomes $(\mathrm{G} \times \mathrm{E}$ and prenatal $\mathrm{E} \times$ postnatal $\mathrm{E})$.

Figure 1 illustrates the interrelation of the studies and the developmental periods covered. EGDS-Toddlers focused on the infancy and toddlerhood period; EGDS-Prenatal expanded EGDS-Toddlers by adding 200 new cases, adding DNA collection on all 561 children and their birth and adoptive parents, and focusing specifically on the role of prenatal influences. Assessments for EGDS-Toddlers and EGDS-Prenatal are complete, with the exception that coding and DNA assaying activities are ongoing. EGDS-School was designed to continue assessments of EGDS-Toddlers participants through the school entry period, with additional data collection specific to school readiness, academic achievement, and stress reactivity (measured by salivary cortisol collection). EGDS-NIMH focuses specifically on child and adoptive parent mental health symptoms and diagnoses. EGDS-Health includes an examination of pathways to healthy weight and obesity through the assessment of family nutrition practices, exercise habits, and body mass indices of all participants. EGDS-School, EGDS-NIMH, and EGDS-Health assessments are ongoing.

\section{Sample Description}

The EGDS sample includes 561 linked sets of participants: 561 adopted children, their adoptive parents (552 adoptive fathers and 567 adoptive mothers; this includes 41 same-sex parent families), their birth mothers $(n=554)$, and their birth fathers $(n=208)$. Just over half of the children are male (57.2\%), and 55.6\% of the children are Caucasian, $19.3 \%$ are more than one race (multiracial), $13 \%$ are African American, $10.9 \%$ are Latino, $<1 \%$ are Asian, $<1 \%$ are American Indian, and $<1 \%$ are of unknown ethnicity/not reported. The median child age at adoption placement was 2 days $(M=6.2, S D=12.45$; range $=0-91$ days). Adopted children's birth dates ranged from January 2003 to May 2009. Demographic information regarding parent age, race, education, marital status, and income at the first wave of data collection (when the child was $4-9$ months old) is provided in Table 1. Cohort differences were examined for all demographic variables, and negligible differences were identified (Cohort I adoptive parent 1's (usually the mother) were approximately one year younger than Cohort II adoptive parent 1's, and both adoptive parents in Cohort I had slightly lower incomes than adoptive parents in Cohort II).

As is indicated by these demographic statistics, EGDS shows the typical pattern of differences in sociodemographic characteristics often found between birth and adoptive parents, with adoptive parents having more advantaged socioeconomic background than birth parents (DeFries et al., 1994). Further, the adoptive families in EGDS generally had higher education and income levels than non-adoptive parents of young children (Bramlett, 2011 ), and higher incomes than the average US household income of $\$ 54,489$ (for 2007; DeNavas-Walt, Proctor, \& Smith, 2012). These elevated levels are expected given the financial costs incurred by adoptive families when completing a domestic adoption placement, and also suggests the utility of adoption as an intervention on the sociodemographic environments of young children. It further indicates potential restriction of range in the environment to be biased toward families with higher sociodemographic backgrounds, as has been noted in prior reviews of the adoption design (Stoolmiller, 1999). However, a systematic test of range restriction biases has shown negligible effects on estimates of heritability and the environment, even when range restriction was present (McGue et al., 2007).

\section{Sample Recruitment}

The EGDS recruitment procedures were designed to accomplish the following: (1) to reduce the likelihood of recruiting only one member of the adoption triad (child, adoptive parents, 
and birth parents); (2) to minimize potential ethical concerns by not initiating contact until after the period of revocation; (3) to minimize the probability that participation in the study would cause information to be transferred across participants, including adoption agencies; (4) to recruit a sample that would contain ethnic diversity and varying levels of adoption openness (contact and knowledge between birth and adoptive families); and (5) to recruit a large subsample of birth fathers. This complex recruitment strategy entailed the collaboration of four recruitment sites: the Mid-Atlantic (George Washington University and The Pennsylvania State University), the West/Southwest (University of California, Davis and University of California, Riverside), the Mid-West (University of Minnesota), and the Pacific Northwest (Oregon Social Learning Center).

Recruitment occurred between March 2003-January 2010 with the recruitment of adoption agencies into the study ( $N=45$ agencies in 15 states). The agencies reflected the full range of US adoption agencies: public, private, religious, secular, those favoring more open adoptions, and those favoring more closed adoptions. Adoption agencies often work in multiple states, and some participants have moved residences since the adoption placement; thus, EGDS participants currently reside in 46 states, the District of Columbia in the US, and in 7 other countries. Each adoption agency appointed a liaison from their organization to perform the initial stages of recruitment into the study. Liaisons received recruitment training by EGDS staff, and agencies were provided an honorarium for their efforts assisting with recruitment.

\section{Inclusion criteria}

Agency liaisons identified participants who completed an adoption plan through their agency and met the study's eligibility criteria: (a) the adoption placement was domestic, (b) placement occurred within 3 months postpartum, (c) the infant was placed with an adoptive family that was not biologically related to the child, (d) there were no known major medical conditions such as extreme prematurity or extensive medical surgeries, and (e) the birth and adoptive parents were able to understand English at the 8th-grade level. All types of adoptive families were eligible for study enrollment (e.g., same-sex parents, single parents, and hearing-impaired parents). A total of 3293 triads met the study criteria. A flow chart of the recruitment procedures is illustrated in Figure 2 with the left bolded column indicating the path to successful recruitment into the study.

\section{Initial recruitment by agency liaison}

Once eligibility criteria were met, $2-4$ weeks post placement, the agency liaison mailed a letter describing the study to each eligible adoptive family. Adoptive families were given the opportunity to opt out of future study contact by returning a self-addressed, stamped postcard. Two weeks after the mailing, liaisons called the birth mothers linked to the adoptive families that had not opted out of study contact ( $80 \%$ of the adoptive families). In this call, the liaison described the study and asked for permission to have a recruiter from the study contact her directly.

\section{Recruitment of birth mothers by project staff}

If birth mothers provided permission for EGDS to contact them (89\% of the time), the EGDS birth parent recruiter contacted the birth mother. Once the birth mother returned a signed consent form via postage-paid mail and began the assessment, she was considered an active study participant (79\%). The project employs separate birth parent and adoptive family recruiters to ensure that project staff do not transfer information between members of the adoption triad. We maintain this separation through all stages of the study, including assessment. 


\section{Recruitment of adoptive families by project staff}

Next, the EGDS adoptive family recruiter attempted to recruit the adoptive family using contact information provided by the agency. If the adoptive parents agreed to participate, they were sent informed consent forms and additional study information. Like birth mothers, adoptive parents were considered recruited once they returned a signed informed consent form and began the first assessment (65\%).

At any point, if the birth mother or adoptive family declined participation or was unable to be contacted, recruitment efforts for that adoption triad ceased. However, once an individual had consented to participate, that individual continued as a participant. Such unlinked participants are not considered as part of our sample of 561 adoption triads but are included in analyses examining questions specific to birth parents or specific to adoptive families.

\section{Recruitment of birth fathers by project staff}

After the birth mother and adoptive parents were recruited, project staff attempted to recruit the birth father. The EGDS has the largest sample of directly studied birth fathers in an adoption study and is the only study to assess birth fathers longitudinally; we have recruited and assessed birth fathers in $37 \%$ of our participating triads $(n=208)$. Project staff attempted to recruit the birth father using the procedures outlined in the birth mother recruitment section. If the agency liaison did not know or could not reach the birth father, a project staff member asked the birth mother if she was willing to answer some questions about the birth father to help the study locate him and invite him to participate. In addition, recruitment efforts for birth father continue at later waves, which has helped us to recruit additional birth fathers on an ongoing basis.

As is shown in Figure 2, project recruitment staff had low rates of declines (2\% of birth mothers, $20 \%$ of adoptive families, and $8 \%$ of birth fathers). Most nonparticipation resulted from the inability of the agency or the project to locate and contact a potential participant. Minimal systematic sampling biases were detected in recruitment, as shown in Table 2. Data for comparisons in Table 2 were derived with the assistance of our participating adoption agencies, who recorded the education, income, and age of all birth and adoptive parents who met the EGDS inclusion criteria and completed an adoption plan through their agency during the EGDS enrollment period. We compared the demographic information between triads who participated in the EGDS ( $N=561$ triads) with those of the eligible nonparticipants ( $N=2,391$ triads available for analysis). As shown in Table 2, four comparisons reached statistical significance at our set threshold $(p<.01)$, and they proved trivial in practical terms (e.g., participating birth mothers, birth fathers, and adoptive parents were slightly younger than the eligible nonparticipants). There were no significant demographic differences between birth mothers for whom birth fathers were recruited and birth mothers for whom birth fathers were not recruited, with one exception: birth mothers with non-participating birth fathers were less likely to be married or in a similarly committed relationship than birth mothers with participating birth fathers. These comparisons suggest that the EGDS sample is representative of the population from which it was drawn.

\section{Assumptions Underlying the Adoption Design: Openness and Selective Placement}

The adoption design rests on several assumptions about the separate influences of genetic and environmental influences on child development. For example, once intrauterine factors such as prenatal alcohol and drug consumption, maternal depression and stress, and exposure to environmental toxins have been considered, similarities between the birth parent 
and adoptive child can be assumed to result from genetic factors. Trends in adoption practices such as openness (contact and knowledge between birth and adoptive families) and selective placement (agency matching of birth and adoptive parent characteristics) can pose a threat to these assumptions and can bias model estimates. For example, adopted children might be more likely to resemble their birth parents (inflating genetic estimates) if birth parents are in direct contact with the child. Thus, we examined the variation in two aspects of the adoption process - openness and selective placement—with our sample of 561 participating families.

The level of openness was measured by asking birth parents and adoptive parents to report on the amount of contact and knowledge between them. Responses were categorized into seven discrete categories: very closed (no information about the adoptive parents or birth parents), closed (only general information that the agency provided), mediated (written communication only, conducted through an agency), semi-open (exchange of letters and emails, cards, and pictures, but no face-to-face contact), open (visits one to three times per year and communication semi regularly by telephone, mail, or email), quite open (visits about every other month and frequent communication by telephone, mail, or email), and very open (visits at least once monthly and communication several times a month by telephone, mail, or email). The prevalence of each level of openness during infancy as rated by birth and adoptive parents is shown in Table 3. Results suggest significant variation in openness across the sample. In addition, birth mothers, adoptive mothers, and adoptive fathers were in strong agreement about the level of openness $(r=.71-.84)$. We have included a composite measure of openness in all EGDS papers to date, and in only one case was openness significantly associated with the parent and child variables in the models (Leve et al., 2012), suggesting minimal potential for bias.

To test for selective placement, we correlated birth parent characteristics with adoptive family characteristics that were unlikely to be influenced by evocative effects (e.g., scales of personality, self-worth, executive function, temperament, intelligence, and financial needs). Of 132 comparisons, only 3 were statistically significant at $p<.05$. Thus, systematic selective placement biases have not been detected in the EGDS sample.

\section{Data Collection}

Measurement for the EGDS has been guided by four principles: adherence to a theoretical model guiding the domains of assessment between parents and children, utilization of a multimethod multiagent assessment strategy, use of identical or developmentallycomparable measures across assessments to facilitate the examination of change over time, and repeated assessment of birth parents to attempt to more fully capture genetic influences on development through the reduction of measurement error in the birth parent assessments.

\section{Overview of assessment}

The EGDS assessments include questionnaires, in-person interviews, and standardized testing for birth parents, adoptive parents, and children; diagnostic interviews with adoptive parents (about themselves and about the adopted child) and birth parents; observational interactions (mother-father, mother-child, father-child, and mother-father-child) for adoptive families; food and activity diaries for adoptive families; medical records for birth parents and the adopted child; DNA collection via buccal cells for adopted children, adoptive parents, and birth parents; diurnal cortisol measures for adopted children and birth parents; teacher questionnaires for children; and official arrest records for birth parents. The interviews include interviewer-administered questions, which create a context whereby the interviewer can establish rapport with the participant, and computer-assisted personal interviews (CAPI) that are completed privately by participants to facilitate confidentiality 
and honest responses. In-person assessments (adoptive family: age 9 months, 18 months, 27 months, and age 4.5, 6, 7, and 8 years; birth parents: 4- and 18-months postpartum and 4.5 years postpartum) last approximately $3-4 \mathrm{hrs}$ each and are conducted in a location convenient for the participant, most often at home.

Brief telephone interviews (15 minutes) are conducted for birth and adoptive parents in between the primary in-person assessments and last approximately 15 minutes. These also serve as a means of maintaining contact and rapport with participants. Overall, 149 different assessment measures have been administered focusing on the primary theoretical model and aims. A full listing of study measures can be found within our study website: https:// www.egdstudy.org/measures.

\section{Summary of Results}

Our hypothesis testing to date has focused on the completed waves of data (through child age 4.5 for Cohort I and through child age 27 months for Cohort II; published age 6 data were not yet available as of the writing of this report). Table 4 provides a summary of the main foci that have been examined and published. The largest area of emphasis has been on examining environmental influences on child temperament and behavior problems (General Hypothesis 1). In particular, we have focused on parenting, marital relations, and parent mental health predictors of child adjustment outcomes. Our findings regarding General Hypothesis 1 indicate main effects of parenting (overreactive parenting, responsivity, parenting efficacy, and observed structured guidance), marital hostility, and adoptive parent depressive symptoms and anxiety on child temperament and behavioral outcomes, as early as 9 months of age (e.g., Leve et al., 2009; Natsuaki et al., 2010; Mannering et al., 2011). Many of these papers have used longitudinal data and/or observational data (e.g., Leve et al., 2012; Rhoades et al., 2012). In addition, many of the analyses have focused on both adoptive mothers and fathers, with results typically showing unique effects of fathers (e.g., Harold et al., in press; Stover et al., 2012). Although main effects of parenting, marital function, and parent psychopathology are not new to the field of psychology, EGDS is able to show that associations between these family characteristics and child psychosocial adjustment are not solely a function of passive gene-environment correlation, and that they can be detected very early in development.

General Hypothesis 2 examines evocative rGE. In analyses to date, we have found little evidence for evocative $r \mathrm{GE}$ during the early childhood developmental period. We hypothesize that the lack of $r \mathrm{GE}$ effects may be due to the young age of the children (Scarr $\&$ McCartney, 1983), and that we will begin to see evidence for evocative $r \mathrm{GE}$ as the children enter the preschool and school-age periods.

General Hypothesis 3 examines environmental moderation of genetic influences and genetic moderation of environmental influences $(\mathrm{G} \times \mathrm{E})$. We have found significant $\mathrm{G} \times \mathrm{E}$ effects during infancy and toddlerhood for several types of child behavior, including toddler externalizing and total problems (Leve et al., 2009; Lipscomb et al., 2012), attention behavior (Brooker et al., 2011; Leve et al., 2010), fussiness and anger (Natsuaki et al., 2010; Rhoades et al., 2011), and inhibition (Natsuaki et al., in press b). We have also found $\mathrm{G} \times \mathrm{E}$ interaction effects on preschoolers' cortisol regulation (Laurent et al., 2012b). This strong set of $\mathrm{G} \times \mathrm{E}$ findings during early childhood is typically not found in twin studies during this developmental period, and may be the result of the different strengths of the adoption and twin approaches. In the adoption design, we cannot estimate genetic influences as effectively as twin studies can, and thus genetic influences are inferred through measured associations between birth parent and child. Similarly, environmental influences are directly measured in the adoption design through characteristics of the rearing environment. In 
comparison, twin studies estimate genetic and environmental influences using variation in sibling similarity. In $\mathrm{G} \times \mathrm{E}$ analyses, the most common strategy in twin analyses is to examine how these genetic and environmental influences may be moderated by the environment. These methodological differences, combined with the fact that there are few studies of twins as young as the EGDS sample, likely explain the different patterns of G×E findings in the two approaches.

General Hypothesis 4 purports to examine longitudinal pathways of continuity and change across development in relation to genetic and environmental influences. Our analyses suggest fairly high stability of child behavior, parenting behavior, and marital behavior across early childhood (e.g., Lipscomb et al., 2011; Mannering et al., 2011), and indicates that changes in parenting are associated with changes in child behavior (Lipscomb et al., 2012). Further, the influence of genetic risk on trajectories of child externalizing problems was greatest among children who received lower levels of overreactive parenting from their mothers (Lipscomb et al., 2012). General Hypothesis 5-to examine moderation of evocative $r$ GE effects - has not been examined to date given the lack of evocative $r \mathrm{GE}$ effects during toddlerhood.

Overall, the findings to date contribute in novel ways by showing that family environmental variables (e.g., parenting, parental psychopathology, and marital relations) are associated with child adjustment outcomes even when passive $r$ GE effects are removed, and that specific G×E effects can be detected during early childhood. However, results from this study are just one source of knowledge about the interplay between genetic and environmental influences on development during early childhood, and there is a need to synthesize findings across multiple design types. For example, while the adoption design is well powered for detecting environmental (but not genetic) effects, twin studies are among the most powerful designs for detecting genetic effects. However, twin studies are underpowered for identifying shared environmental influences and for specifying which environmental factors are influencing development (Plomin et al., 2013). Together, the results across designs suggest the importance of family environmental effects (EGDS results) and genetic influences (twin studies) on child behavioral adjustment.

\section{Future Plans}

As new waves of data are collected, we will continue to examine the original aims and hypotheses across development, and using longitudinal modeling approaches. As noted earlier, we are particularly keen to test whether evocative $r$ GE effects emerge as children enter school and have more experiences outside of the family system. In addition, assaying of the DNA samples will allow us to examine whether some of our published G×E findings can be replicated using molecular genetic approaches. We have nearly completed genotyping of 11 polymorphisms, and may, in future years, expand to a sequencing approach. We do not have sufficient power for GWAS analyses and these are therefore not planned. Similarly, through ongoing collection of the diagnostic interview data and of the food and activity diaries, we will be able to test hypotheses relating to GE interplay on early emerging mental health symptoms and weight trajectories in children-two areas with great public health impact.

\section{Additional hypotheses requiring new data collection}

In addition to addressing the original study aims, we are also seeking funding to extend the scope of EGDS in four ways. First, to better understand how genes, prenatal exposures, and rearing environments work together to influence child development, we seek to follow the Cohort II participants through middle childhood to age 8 . Second, we would like to better understand how genes and environments jointly influence sleep. To pursue this objective, 
we plan to use sleep actigraphy methods and sleep diaries to measure child and adult sleep patterns over time. Third, we would like to understand the transition to middle school for Cohort I participants and are seeking funding to assess children from age $10-12$. Finally, we would like to add a unique sample of biological siblings of the EGDS participating children to the study. Specifically, birth parents of children participating in EGDS who are also rearing at least one biological child would be recruited and family processes in the biological homes would be examined. Although we do have current plans to recruit a nonadoptive control sample of families, we have sought collaborations with other researchers who have conducted studies of similarly-aged children and are planning a series of manuscripts that examine child adjustment and family processes across a range of family types (e.g., see Harold et al., in press). Each of these proposed data extensions is currently under consideration for future funding.

\section{Acknowledgments}

This project was supported by R01 HD042608, NICHD, NIDA, and OBSSR, NIH, U.S. PHS (PI Years 1-5: David Reiss; PI Years 6-10: Leslie D. Leve), R01 DA020585 NIDA, NIMH, and OBSSR, NIH, U.S. PHS (PI: Jenae Neiderhiser, Ph.D.), R01 MH092118, NIMH, NIH, U.S. PHS (PIs: Jenae Neiderhiser, Ph.D. and Leslie Leve, Ph.D.), and R01 DK090264, NIDDK, NIH, U.S. PHS (PI: Jody Ganiban, Ph.D.). The content is solely the responsibility of the authors and does not necessarily represent the official views of the Eunice Kennedy Shriver National Institute of Child Health \& Human Development or the National Institutes of Health.

We would like to thank the birth and adoptive parents who participated in this study and the adoption agencies who helped with the recruitment of study participants. Special gratitude is given to Rand Conger, John Reid, Xiaojia Ge, and Laura Scaramella who contributed to the larger study aims, to Amy Whitesel, Danielle Guerrero, and Anna Suski for assistance with project management, and to all our collaborators and co-authors who have developed and tested hypotheses using study data.

\section{References}

Birch LL, Davison KK. Family environmental factors influencing the developing behavior controls of food intake and childhood overweight. Pediatric Clinics of North America. 2001; 48:893-907. [PubMed: 11494642]

Blozis SA, Ge X, Xu S, Natsuaki MN, Shaw DS, Scaramella L, Reiss D. Sensitivity analysis of multiple informant models when data are not missing at random. Structural Equation Modeling. (in press).

Bramlett, MD. The national survey of adoptive parents: Benchmark estimates of school performance and family relationship quality for adopted children. 2011. Retrieved from http://aspe.hhs.gov/hsp/ 09/NSAP/Brief3/rb.shtml.

Brooker RJ, Neiderhiser JM, Kiel EJ, Leve LD, Shaw DS, Reiss D. The association between infants' attention control and social inhibition is moderated by genetic and environmental risk for anxiety. Infancy. 2011; 16:490-507. [PubMed: 21857796]

Button TMM, Scourfield J, Martin N, Purcell S, McGuffin P. Family dysfunction interacts with genes in the causation of antisocial symptoms. Behavior Genetics. 2005; 35:115-120. [PubMed: 15685425]

Cadoret RJ, Winokur G, Langbehn D, Troughton E, Yates WR, Stewart MA. Depression spectrum disease, I: The role of gene-environment interaction. American Journal of Psychiatry. 1996; 153:892-899. [PubMed: 8659611]

Cadoret RJ, Yates WR, Troughton E, Woodworth G, Stewart MA. Genetic-environmental interaction in the genesis of aggressivity and conduct disorders. Archives of General Psychiatry. 1995; 52:916924. [PubMed: 7487340]

Caspi A, Henry B, McGee RO, Moffitt TE, Silva PA. Temperamental origins of child and adolescent behavior problems: From age 3 to age 15. Child Development. 1995; 66:55-68. [PubMed: 7497829]

Caspi A, Roberts BW. Personality development across the life course: The argument for change and continuity. Psychological Inquiry. 2001; 12:49-66. 
DeNavas-Walt, C.; Proctor, BD.; Smith, JC. Income, Poverty, and Health Insurance Coverage in the United States: 2011. Washington, DC: Government Printing Office; 2012.

Deater-Deckard K. Parenting and child behavioral adjustment in early childhood: A quantitative genetic approach to studying family processes. Child Development. 2000; 71:468-484. [PubMed: 10834478]

Deater-Deckard K, O'Connor TG. Parent-child mutuality in early childhood: Two behavioral genetic studies. Developmental Psychology. 2000; 36:561-570. [PubMed: 10976597]

DeFries, JC.; Plomin, R.; Fulker, DW. Nature \& nurture during middle childhood. Cambridge, MA: Blackwell; 1994.

Dunn JF, Plomin R, Daniels D. Consistency and change in mothers' behavior toward young siblings. Child Development. 1986; 57:348-356. [PubMed: 3956317]

Eisenberg N, Valiente C, Morris AS, Fabes RA, Cumberland A, Reiser M, Gershoff ET, Shepard SA, Losoya S. Longitudinal relations among parental emotional expressivity, children's regulation, and quality of socioemotional functioning. Developmental Psychology. 2003; 39:3-19. [PubMed: 12518805]

Ganiban, JM.; Leve, LD.; Moore, G.; Neiderhiser, JM. Strategies for understanding the mechanisms of mothering and fathering. In: Bridges, RS., editor. Neurobiology of the parental brain. Amsterdam, The Netherlands: Elsevier; 2008. p. 391-403.

Ge X, Conger RD, Cadoret RJ, Neiderhiser JM, Yates W, Troughton E, Stewart M. The developmental interface between nature and nurture: A mutual influence model of child antisocial behavior and parent behaviors. Developmental Psychology. 1996; 32:574-589.

Ge X, Natsuaki MN, Martin D, Leve LD, Neiderhiser JM, Shaw DS, et al. Bridging the divide: Openness in adoption and post-adoption psychosocial adjustment among birth and adoptive parents. Journal of Family Psychology. 2008; 22:529-540. [PubMed: 18729667]

Gilliom M, Shaw DS. Codevelopment of externalizing and internalizing problems in early childhood. Development and Psychopathology. 2004; 16:313-334. [PubMed: 15487598]

Harold GT, Leve LD, Elam KE, Thapar A, Neiderhiser JM, Natsuaki MN, et al. The nature of nurture: Disentangling passive genotype-environment correlation from family relationship influences on children's externalizing problems. Journal of Family Psychology. (in press).

Haugaard JJ, Hazan C. Adoption as a natural experiment. Development and Psychopathology. 2003; 15:909-926. [PubMed: 14984132]

Leve LD, Harold GT, Ge X, Neiderhiser JM, Patterson G. Refining intervention targets in familybased research: Lessons from quantitative behavioral genetics. Perspectives on Psychological Science. 2010; 5:516-526. [PubMed: 21188273]

Laurent HK, Leve L, Neiderhiser J, Natsuaki M, Shaw D, Harold G, Reiss D. Effects of prenatal and postnatal parent depressive symptoms on adopted child HPA regulation: Independent and moderated influences. Developmental Psychology. 2012a [Epub ahead of print, 2012 Jun 11].

Laurent HK, Leve LD, Neiderhiser JM, Natsuaki MN, Shaw DS, Fisher PA, et al. Effects of parental depressive symptoms on child adjustment moderated by Hypothalamic Pituitary Adrenal activity: Within- and between-family risk. Child Development. 2012b Advance online publication. NIHMSID: 378573.

Leve LD, DeGarmo DS, Bridgett DJ, Neiderhiser JM, Shaw DJ, Harold GT, et al. Using an adoption design to separate genetic, prenatal, and temperament influences on toddler executive function. Developmental Psychology. 2012 [Epub ahead of print, 2012 Jul 16].

Leve LD, Harold GT, Ge X, Neiderhiser JM, Shaw D, Scaramella LV, Reiss D. Structured parenting of toddlers at high versus low genetic risk: Two pathways to child problems. Journal of the American Academy of Child and Adolescent Psychiatry. 2009; 48:1102-1109. [PubMed: 19797981]

Leve LD, Kerr D, Shaw D, Ge X, Neiderhiser JM, Reid JB, et al. Infant pathways to externalizing behavior: Evidence of GenotypexEnvironment interaction. Child Development. 2010; 81:340 356. [PubMed: 20331671]

Leve LD, Neiderhiser JM, Ge X, Scaramella LV, Conger RD, Reid JB, et al. The Early Growth and Development Study: A prospective adoption design. Twin Research and Human Genetics. 2007; 10:84-95. [PubMed: 17539368] 
Leve LD, Neiderhiser JM, Scaramella LV, Reiss D. The Early Growth and Development Study: Using the prospective adoption design to examine genotype-environment interplay. [Special section]. Behavior Genetics. 2010; 40:306-314. (Reprinted from 2008 Acta Psychologica Sinica, 40, 11061115). [PubMed: 20358398]

Lipscomb ST, Leve LD, Harold GT, Neiderhiser JM, Shaw DS, Ge X, Reiss D. Trajectories of parenting and child negative emotionality during infancy and toddlerhood: A longitudinal analysis. Child Development. 2011; 82:1661-1675. [PubMed: 21883160]

Lipscomb ST, Leve LD, Shaw DS, Neiderhiser JM, Scaramella LV, Ge X, et al. Negative emotionality and externalizing problems in toddlerhood: Overreactive parenting as a moderator of genetic influences. Development and Psychopathology. 2012; 24:167-179. [PubMed: 22293002]

Mannering AM, Harold GT, Leve LD, Shelton KH, Shaw DS, Conger RD, et al. Longitudinal associations between marital instability and child sleep problems across infancy and toddlerhood in adoptive families. Child Development. 2011; 84:1252-1256. [PubMed: 21557740]

Martin DM, Leve LD, Natsuaki MN, Neiderhiser JM, Ge X. Toward a greater understanding of openness: A report from the Early Growth and Development Study. National Council of Adoption's Factbook V. 2011:471-477.

Massey SH, Lieberman DZ, Reiss D, Leve LD, Shaw D, Neiderhiser JM. Association of clinical characteristics and cessation of tobacco, alcohol and illicit drug use during pregnancy. American Journal on Addictions. 2011; 20:143-150. [PubMed: 21314757]

Massey SH, Neiderhiser JM, Shaw DS, Leve LD, Ganiban JM, Reiss D. Maternal self concept as a provider and cessation of substance use during pregnancy. Addictive Behaviors. 2012; 37:956961. [PubMed: 22575401]

McClelland, MM.; Leve, LD.; Pears, KC. Preschool executive functions in the context of family risk. In: Griffin, JA.; Freund, LS.; McCardle, P., editors. Executive function in preschool age children: Integrating measurement, neurodevelopment and translational research. (in press).

McGue M, Keyes M, Sharma A, Elkins I, Legrand L, Johnson, Iacono WG. The environments of adopted and non-adopted youth: Evidence on range restriction from the sibling interaction and behavior study (SIBS). Behavior Genetics. 2007; 37:449-462. [PubMed: 17279339]

Natsuaki MN, Ge X, Leve LD, Neiderhiser JM, Shaw DS, Conger RD, et al. Genetic liability, environment, and the development of fussiness in toddlers: The roles of maternal depression and parental responsiveness. Developmental Psychology. 2010; 46:1147-1158. [PubMed: 20822229]

Natsuaki MN, Leve LD, Harold GT, Neiderhiser JM, Shaw DS, Ganiban J, et al. Transactions between child social wariness and observed structured parenting: Evidence from a prospective adoption study. Child Development. (in press a).

Natsuaki MN, Leve LD, Neiderhiser JM, Shaw DS, Scaramella LV, Ge X, Reiss D. Intergenerational transmission of risk for social inhibition: The interplay between parental responsiveness and genetic influences. Development and Psychopathology. (in press b).

Neiderhiser JM, Reiss D, Lichtenstein P, Spotts EL, Ganiban JM. Father-adolescent relationships and the role of genotype-environment correlation. Journal of Family Psychology. 2007; 21:560-571. [PubMed: 18179328]

Olds, DL.; Robinson, J.; Song, N.; Little, C.; Hill, P. Reducing risks for mental disorders during the first five years of life: A review of the literature. Rockville, MD: Substance Abuse and Mental Health Services Administration; 2005.

Pemberton CK, Neiderhiser JM, Leve LD, Natsuaki MN, Shaw DS, Reiss D, Ge X. Influence of parental depressive symptoms on adopted toddler behaviors: An emerging developmental cascade of genetic and environmental effects. Development and Psychopathology. 2010; 22:803-818. [PubMed: 20883583]

Petrill SA, Deater-Deckard K, Thompson LA, DeThorne LS, Schatschneider C. Reading skills in early readers: Genetic and shared environmental influences. Journal of Learning Disabilities. 2006; 39:48-55. [PubMed: 16512082]

Plomin, R.; DeFries, JC. Origins of individual differences in infancy: The Colorado Adoption Project. Orlando, FL: Academic Press; 1985.

Plomin, R.; DeFries, JC.; Knopik, VS.; Neiderhiser, JM. Behavioral Genetics. 6th edition. New York: Worth Publishers; 2013. 
Reiss D, Leve LD. Genetic expression outside the skin: Clues to mechanisms of Genotype $\times$ Environment interaction. Development and Psychopathology. 2007; 19:1005-1027. [PubMed: 17931431]

Reiss, D.; Leve, LD.; Whitesel, A. Understanding links between birth parents and the child they have placed for adoption: Clues for assisting adopting families and for reducing genetic risk. In: Wrobel, GM.; Neil, E., editors. International advances in adoption research for practice. New York: John Wiley; 2009. p. 119-146.

Reiss, D.; Neiderhiser, J.; Hetherington, EM.; Plomin, R. The Relationship Code: Deciphering genetic and social patterns in adolescent development. Cambridge, MA: Harvard University Press; 2000.

Rhoades KA, Leve LD, Harold GT, Mannering AM, Neiderhiser JM, Shaw DS, et al. Marital hostility and child sleep problems: Direct and indirect associations via hostile parenting. Journal of Family Psychology. 2012; 26:488-498. [PubMed: 22888782]

Rhoades KA, Leve LD, Harold GT, Neiderhiser JM, Shaw DS, Reiss D. Longitudinal pathways from marital hostility to child anger during toddlerhood: Genetic susceptibility and indirect effects via harsh parenting. Journal of Family Psychology. 2011; 25:282-291. [PubMed: 21480707]

Scarr S, McCartney K. How people make their own environments: A theory of genotype? $\rightarrow$ ? environment effects. Child Development. 1983; 54:424-435. [PubMed: 6683622]

Stoolmiller M. Implications of the restricted range of family environments for estimates of heritability and nonshared environment in behavior-genetic adoption studies. Psychological Bulletin. 1999; 125:392-409. [PubMed: 10414224]

Stover CS, Connell C, Leve LD, Neiderhiser JM, Shaw DS, Scaramella LV, Conger R, Reiss D. Relationship among marital hostility, father's hostile parenting and toddler aggression in adoptive families. Journal of Child Psychology and Psychiatry. 2012; 53:401-409. [PubMed: 22191546] 


\begin{tabular}{|c|c|c|c|c|c|c|c|c|c|c|}
\hline & Child Age & $4 \mathrm{mo}$ & $9 \mathrm{mo}$ & $18 \mathrm{mo}$ & $27 \mathrm{mo}$ & $4.5 \mathrm{yrs}$ & $6 \mathrm{yrs}$ & 7 yrs & 8 yrs & 9 yrs \\
\hline \multirow{4}{*}{$\begin{array}{l}\text { Birth } \\
\text { Parent }\end{array}$} & \multirow[t]{2}{*}{ Cohort I } & $\begin{array}{l}N=361 \\
2003- \\
2010\end{array}$ & & $\begin{array}{l}N=354 \\
2004 \\
2011\end{array}$ & & $\begin{array}{l}N=338 \\
2008- \\
2013\end{array}$ & & & & $\begin{array}{l}N=187^{*} \\
2012- \\
2016\end{array}$ \\
\hline & & \multicolumn{3}{|c|}{ EGDS Toddlers } & & $\begin{array}{l}\text { EGDS } \\
\text { School }\end{array}$ & & & & $\begin{array}{l}\text { EGDS } \\
\text { Health }\end{array}$ \\
\hline & \multirow[t]{2}{*}{ Cohort II } & $\begin{array}{l}N=200 \\
2007- \\
2012\end{array}$ & & $\begin{array}{l}N=195 \\
2008- \\
2012\end{array}$ & & & & $\begin{array}{l}N=2 * \\
2013- \\
2016\end{array}$ & & \\
\hline & & \multicolumn{3}{|c|}{ EGDS Prenatal } & & & & $\begin{array}{l}\text { EGDS } \\
\text { Health }\end{array}$ & & \\
\hline \multirow{4}{*}{$\begin{array}{c}\text { Adoptive } \\
\text { Family } \\
\text { (adoptive } \\
\text { parents, } \\
\text { adopted } \\
\text { child) }\end{array}$} & \multirow[t]{2}{*}{ Cohort I } & & $\begin{array}{l}N=358 \\
2003- \\
2006\end{array}$ & $\begin{array}{l}N=352 \\
2004- \\
2007\end{array}$ & $\begin{array}{l}N=340 \\
2005- \\
2009\end{array}$ & $\begin{array}{l}N=304 \\
2007- \\
2010\end{array}$ & $\begin{array}{l}N=310 \\
2009- \\
2012\end{array}$ & $\begin{array}{l}N=268 * \\
2010- \\
2013\end{array}$ & $\begin{array}{l}N=136^{*} \\
2011- \\
2014\end{array}$ & $\begin{array}{l}N=31 * \\
2012- \\
2015\end{array}$ \\
\hline & & & \multicolumn{3}{|c|}{ EGDS Toddlers } & \multicolumn{3}{|c|}{ EGDS School } & $\begin{array}{l}\text { EGDS } \\
\text { NIMH }\end{array}$ & $\begin{array}{l}\text { EGDS } \\
\text { Health }\end{array}$ \\
\hline & \multirow[t]{2}{*}{ Cohort II } & & $\begin{array}{l}N=196 \\
2008- \\
2010\end{array}$ & $\begin{array}{l}N=193 \\
2008- \\
2010\end{array}$ & $\begin{array}{l}N=191 \\
2009- \\
2011\end{array}$ & & $\begin{array}{l}N=0 * \\
2013- \\
2015\end{array}$ & $\begin{array}{l}N=0 * \\
2015- \\
2016\end{array}$ & & \\
\hline & & & \multicolumn{3}{|c|}{ EGDS Prenatal } & & $\begin{array}{l}\text { EGDS } \\
\text { NIMH }\end{array}$ & $\begin{array}{l}\text { EGDS } \\
\text { Health }\end{array}$ & & \\
\hline
\end{tabular}

Figure 1.

Timeline for the EGDS studies and assessments. *Assessments are currently ongoing; final $n$ will be higher. 


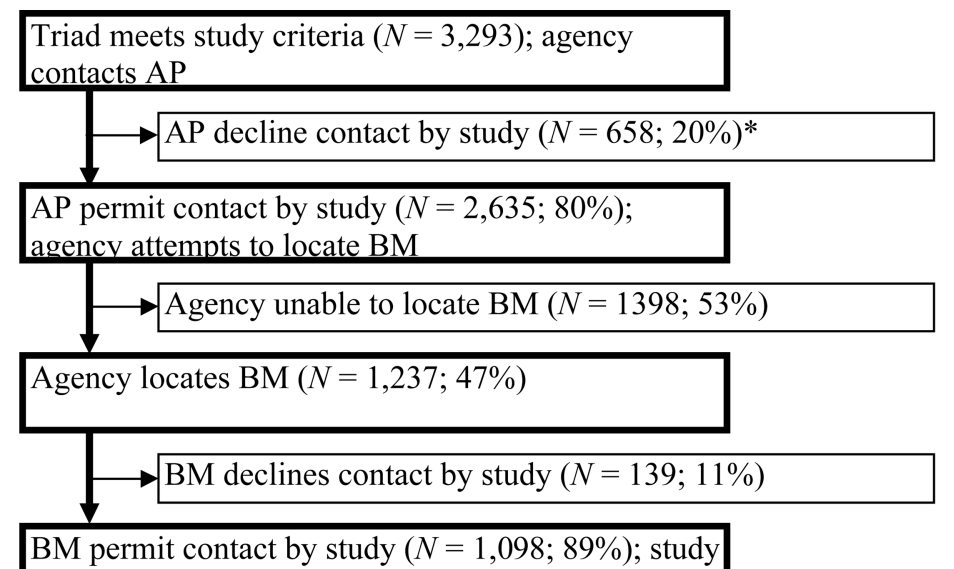
attempts to recruit BM

\begin{tabular}{ll}
$\longrightarrow$ Study unable to locate $\mathrm{BM}(N=138 ; 12 \%)$ \\
\hline
\end{tabular}
attempts to recruit $\mathrm{BF}$

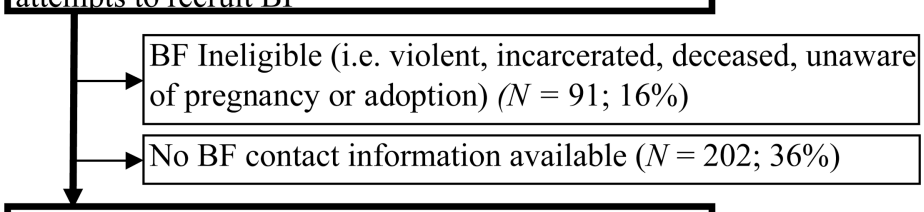

BF contact information available $(N=268 ; 48 \%)$

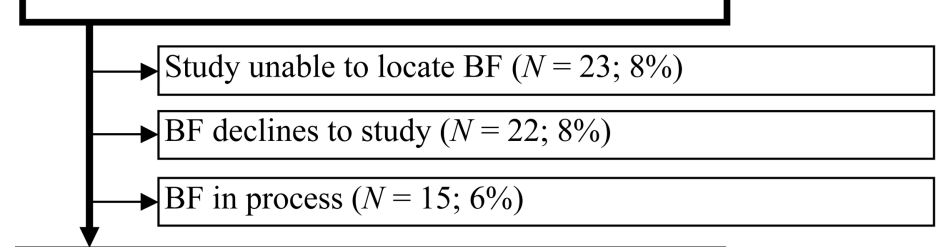

BF recruited by study $(N=208 ; 78 \%)$

Figure 2.

Recruitment flow chart. $\mathrm{AP}=$ adoptive parents. $\mathrm{BF}=$ birth father. $\mathrm{BM}=$ birth mother.

*Percentiles for each box correspond to the proportion relative to the bolded box above it. 


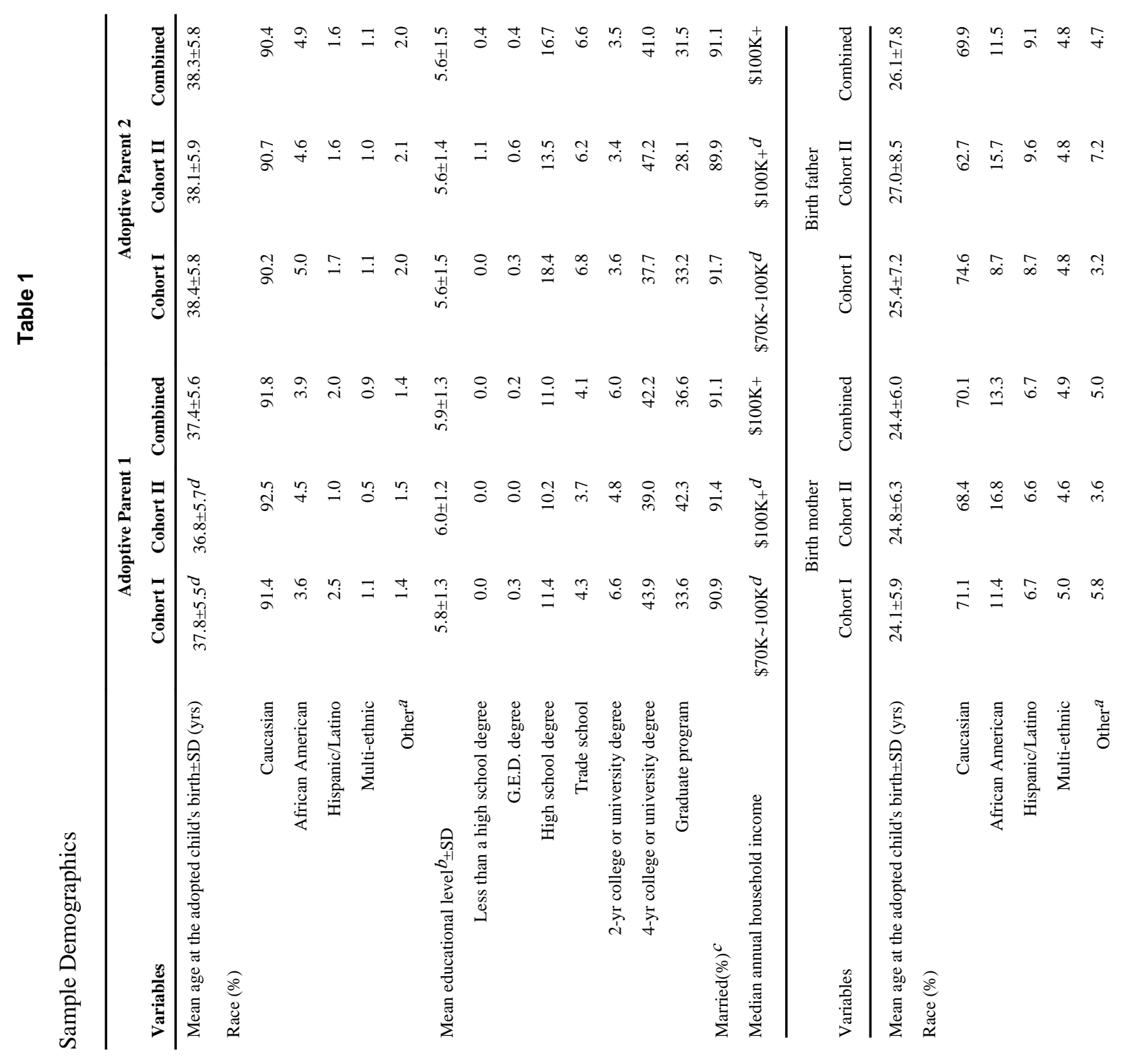




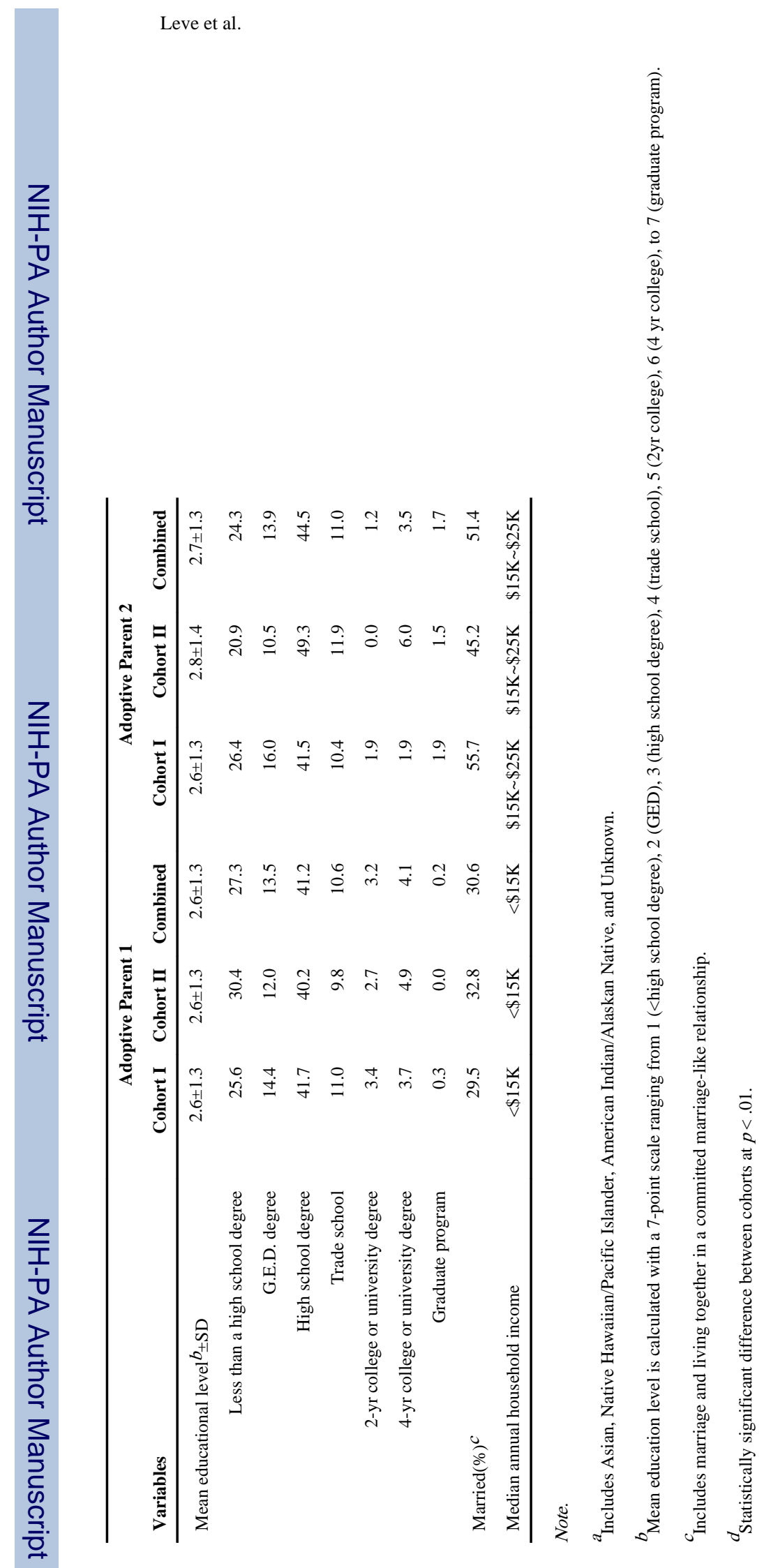

Twin Res Hum Genet. Author manuscript; available in PMC 2013 February 14 


\section{Table 2}

Comparison Between EGDS Participants and Eligible Nonparticipants on Education, Income, and Age $(\mathrm{N}=$ 561 participants and 2,391 eligible nonparticipants)

\begin{tabular}{lrrr}
\hline Variable & Participants $\boldsymbol{M}(\boldsymbol{S D})$ & Nonparticipants $\boldsymbol{M ( S D )}$ & $\boldsymbol{p}$ \\
\hline BM education & $4.23(2.46)$ & $4.01(2.32)$ & \\
BM income & $1.18(0.60)$ & $1.20(0.60)$ & \\
BM age & $24.01(6.23)$ & $24.83(6.41)$ & $p<.01$ \\
BF education & $4.16(2.31)$ & $4.00(2.28)$ & \\
BF income & $1.23(0.55)$ & $1.24(0.52)$ & \\
BF age & $25.67(7.63)$ & $27.54(8.51)$ & $p<.01$ \\
AP1 education & $9.09(1.84)$ & $8.61(2.28)$ & $p<.01$ \\
AP1 age & $36.82(5.56)$ & $37.60(5.97)$ & $p<.01$ \\
AP2 education & $8.77(2.29)$ & $8.45(2.43)$ & \\
AP2 age & $37.76(6.02)$ & $38.51(6.27)$ & \\
AP income & $5.08(1.15)$ & $5.01(1.19)$ & \\
\hline
\end{tabular}

Note. The information was provided by adoption agencies during the study enrollment period. $\mathrm{BM}=$ birth mother. $\mathrm{BF}=$ birth father. $\mathrm{AP}=$ adoptive parent. Education was assessed via an 11-point scale with 1 (<8th grade), 2 (completed 8th grade), 3 (completed 12th grade), 4 (some trade school), 5 (completed trade school), 6 (some 2-year college or university), 7 (completed 2-year college or university degree), 8 (some 4-year college or university), 9 (completed 4-year college or university degree), 10 (some professional/graduate school), and 11 (completed professional/graduate school). Income was measured with a 6-point scale with 1 (less than $\$ 20 \mathrm{~K}), 3(\$ 40 \mathrm{~K} \sim 59,999), 6(\$ 100 \mathrm{~K}$ or more). 


\section{Table 3}

Self-reported Level of Openness in the Adoption

\begin{tabular}{rrrrr}
\hline Level of openness (\%) & AP 1 & AP 2 & BM & BF \\
\hline Very closed & 0.2 & 0.0 & 0.4 & 4.9 \\
Closed & 4.6 & 6.4 & 3.4 & 5.4 \\
Mediated & 18.4 & 18.1 & 12.0 & 10.3 \\
Semi-open & 15.7 & 15.1 & 15.9 & 21.2 \\
Open & 38.5 & 40.0 & 35.1 & 33.7 \\
Quite open & 14.5 & 13.0 & 17.8 & 13.0 \\
Very open & 8.1 & 7.4 & 15.4 & 11.4 \\
\hline
\end{tabular}

Note. $\mathrm{AP}=$ Adoptive Parent; $\mathrm{BM}=$ Birth Mother; $\mathrm{BF}=$ Birth Father 


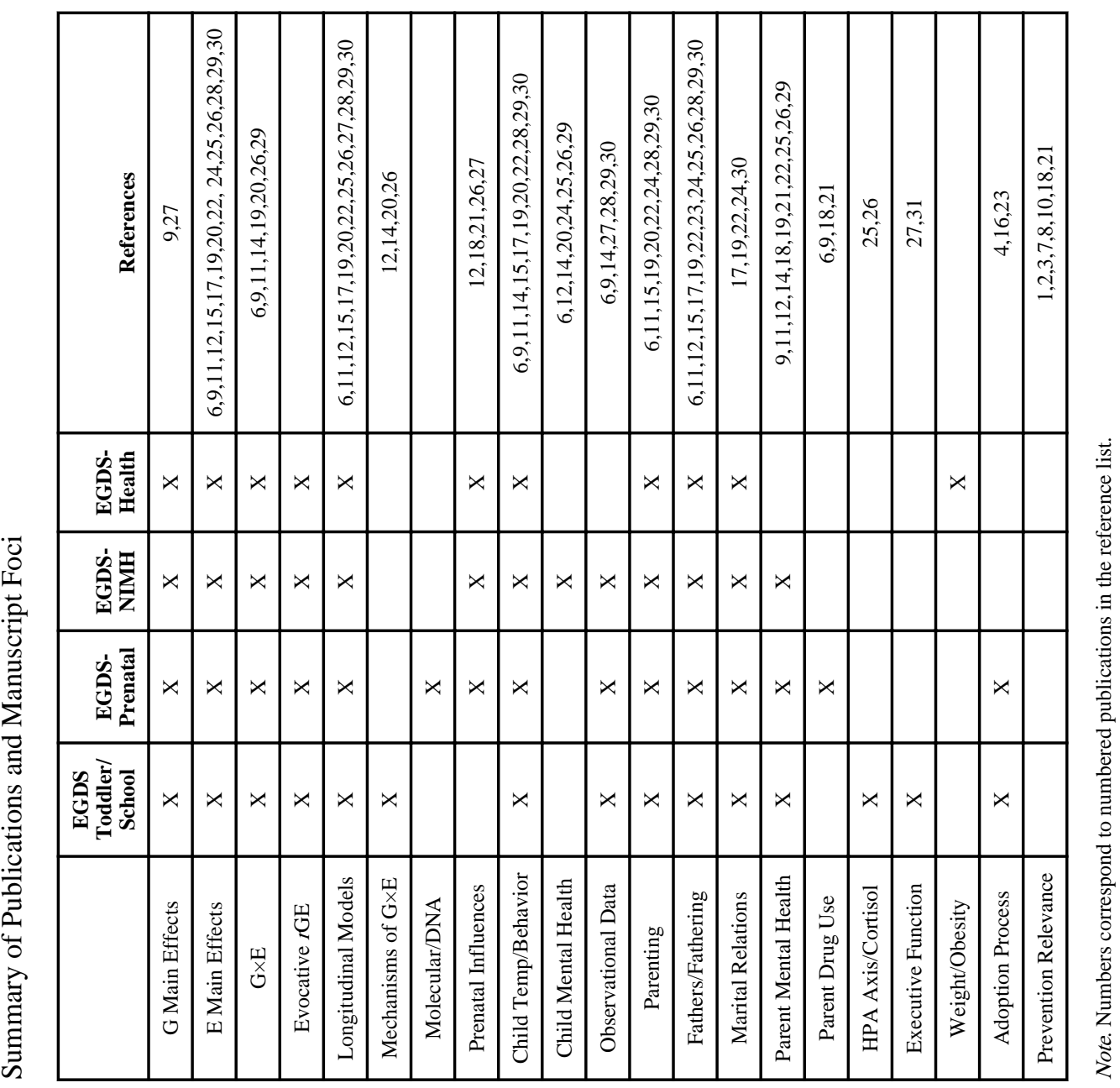

